\title{
Study on Axial Compression Test of Fiber Reinforced Ultra-High Strength Concrete Column Confined by High-Strength Reinforcement
}

\author{
Zhang Mingyang, Tang Xin and Wang Weilun* \\ School of Civil Engineering, Shenzhen University, Shenzhen 518060, China \\ *wang_weilun@hotmail.com
}

Keywords: ultra-high strength concrete; high-strength reinforcement; stress-strain curve; PVA fiber

\begin{abstract}
Axial compression test of 9 high-strength reinforcement confined ultra-high strength concrete with PVA fibers columns were presented. The influence of concrete strength, reinforcement spacing on the behavior of the confined concrete was investigated. The results show that the ductility of columns decrease with the concrete strength increase, and decreasing the reinforcement spacing can increase ductility of columns. In the test, when the confined concrete reached the peak stress, the transverse reinforcement did not yield.
\end{abstract}

\section{Introduction}

High-strength concrete has the characteristics of high strength, high modulus and denser microstructure, and cross-section size of the structural members, weight of the structure can be reduced. Durability of concrete structure is improved. Ultra-high strength concrete is more brittle than normal strength concrete, and the tensile strength is much lower than the compressive strength, and the cracking and fatigue resistance ability is poor. In order to improve these defects of high strength concrete, on one hand, we can introduce the bridging and consumption role of fiber material when bursting and pulling out to improve the tensile strength of concrete; on the other hand, we can combine the high-strength concrete columns with high-strength reinforcement so that the core concrete can be effectively confined to prevent the early buckling; the concrete strength and deformation capacity of concrete were enhanced[1-3]. A lot of researches about high strength concrete columns confined by reinforcement were conducted, and some results have been included in relevant codes [4-9]. In this paper, axial compression test of fiber reinforced ultra-high strength concrete (over $80 \mathrm{Mpa}$ ) columns confined by high-strength reinforcement was conducted, the effect of concrete strength and reinforcement spacing on the behavior of columns was analyzed.

\section{Experimental procedure}

The test consists of 9 high-strength reinforcement confined ultra-high strength concrete columns and 3 plain concrete columns. Dimensions of all test samples are $270 \mathrm{~mm} \times 270 \mathrm{~mm} \times 750 \mathrm{~mm}$, and the concrete cover thickness is $10 \mathrm{~mm}$. The longitudinal reinforcement is HRB500 grade steel with the yield strength 550Mpa. Transverse reinforcement is high tensile strength steel wires with the diameter of $6.5 \mathrm{~mm}$ and the yield strength of $962 \mathrm{Mpa}$. Longitudinal reinforcement ratio is $1.8 \%$ and PVA fiber volume fraction is $0.5 \%$. The details of the specimens was shown in Table 1.Fig. 1 shows the cross section of specimens and arrangement of transverse reinforcement. A concentric compressive load was applied using a hydraulic universal testing machine with a capacity of $10 \mathrm{MN}$. Two measurement length with the $300 \mathrm{~mm}$ and $600 \mathrm{~mm}$ respectively were set up on the specimens, and the axial deformation was measured using LVDT (linear variable differential transducer) arranged symmetrically on both sides of specimens. In addition, strain gauges were used to measure the strain of longitudinal and lateral reinforcement. An overall view of test set up are shown in Fig.2.The loading mode of test was displacement control with the displacement rate of $0.2 \mathrm{~mm} / \mathrm{min}$ until fracture. 


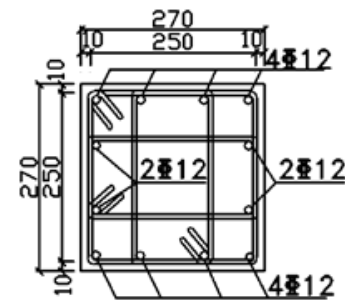

Fig. 1 Cross-sectional Details of Specimens

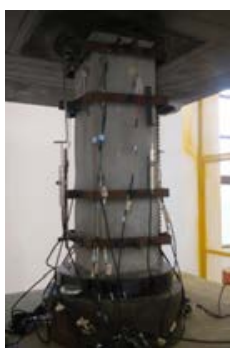

Fig. 2 Overall view of test set-up Table 1. Properties of Specimens and test results

\begin{tabular}{ccccccccccc}
\hline Specimen & $\begin{array}{c}\text { Reinforcement } \\
\text { spacing/mm }\end{array}$ & $\begin{array}{c}f_{c u} \\
/ \mathrm{MPa}\end{array}$ & $\begin{array}{c}f_{c o} \\
/ \mathrm{MPa}\end{array}$ & $\begin{array}{c}\varepsilon_{c o} \\
/\left(\times 10^{-3}\right)\end{array}$ & $\begin{array}{c}f_{c c} \\
/ \mathrm{MPa}\end{array}$ & $\begin{array}{c}\varepsilon_{c c} \\
/\left(\times 10^{-3}\right)\end{array}$ & $\begin{array}{c}\varepsilon_{85} \\
/\left(\times 10^{-3}\right)\end{array}$ & $\begin{array}{c}\varepsilon_{50} \\
/\left(\times 10^{-3}\right)\end{array}$ & $\begin{array}{c}\varepsilon_{s v} \\
/\left(\times 10^{-3}\right)\end{array}$ & $\frac{\varepsilon_{s v}}{\varepsilon_{y v}} / \%$ \\
\hline HSC-A-1 & 140 & 82.5 & 56.20 & 2.42 & 64.15 & 3.29 & 5.90 & 17.32 & 2.02 & 44 \\
HSC-A-2 & 75 & 82.5 & 56.20 & 2.42 & 75.16 & 4.26 & 7.92 & 28.04 & 2.37 & 52 \\
HSC-A-3 & 40 & 82.5 & 56.20 & 2.42 & 87.76 & 5.99 & 11.28 & 34.87 & 3.13 & 68 \\
HSC-B-1 & 140 & 98.4 & 69.67 & 2.66 & 80.17 & 3.18 & 6.15 & 12.64 & 1.88 & 41 \\
HSC-B-2 & 75 & 98.4 & 69.67 & 2.66 & 89.79 & 4.23 & 7.94 & 19.50 & 2.29 & 50 \\
HSC-B-3 & 40 & 98.4 & 69.67 & 2.66 & 97.64 & 5.40 & 10.26 & 29.16 & 2.25 & 49 \\
HSC-C-1 & 140 & 116.8 & 87.55 & 2.96 & 104.8 & 3.15 & 5.00 & 10.30 & 1.74 & 38 \\
HSC-C-2 & 75 & 116.8 & 87.55 & 2.96 & 111.0 & 3.67 & 5.87 & 17.97 & 1.86 & 41 \\
HSC-C-3 & 40 & 116.8 & 87.55 & 2.96 & 122.0 & 4.33 & 8.70 & 24.97 & 2.24 & 49 \\
\hline
\end{tabular}

Note: $f_{c u}$ : 28days compressive cube strength $\left(150 \mathrm{~mm}^{*} 150 \mathrm{~mm}^{*} 150 \mathrm{~mm}\right) ; f_{c o}, \varepsilon_{c o}$ : peak stress and strain of plain concrete columns; $f_{c c}, \varepsilon_{c c}$ :peak stress and strain of confined concrete; $\varepsilon_{85}, \varepsilon_{50}$ : strain corresponding to $0.85 f_{c c}$ and $0.5 f_{c c}$ on the unloading part of stress-strain curve; $\varepsilon_{s v}$ :transverse strain corresponding to peak stress of confined concrete; $\varepsilon_{y v}$ :transverse reinforcement strain corresponding to yield strength of reinforcement.

\section{Observed behavior}

In the initial stage of loading, the specimens shows elastic behavior, the axial deformation of the specimens is very small, and there is no change on the surface of specimens. With the load increasing, some cracks appear on the end of the upper and lower surface of the specimens when the load reaches about $60 \%$ of the axial peak load. The crack development pattern of confined concrete column and non-confined concrete column was different. For the plain concrete columns, the cracks developed slower after cracks appeared on the end, and developed to the center gradually when the load reached about $85 \%$ of peak load. The bearing capacity dropped rapidly when the specimens was suddenly destroyed Compared with reinforcement confined concrete specimens, the cracks are smaller. For reinforcement confined concrete columns, the specimens show plastic deformation when it reached $70 \% \sim 80 \%$ of the ultimate bearing capacity, the load-displacement curve presented nonlinearly, and vertical cracks occured in the middle of the specimens. The cracks on both sides and the middle of the test sample run through gradually with the load increasing. When it approached the peak load of the specimens, the cracks run-through and part of concrete cover crushed and spall with a crackling sound. Compared with specimens with smaller reinforcement ratio, spall of concrete cover of the columns with larger reinforcement ratio were severely.

After the reinforcement confined concrete columns reach the peak load, the capacity has a small decline section suddenly, the axial and transverse deformation of concrete increase rapidly, resulting in rapid increase of lateral reinforcement stress, then reinforcement play an effective confinement role, and the load decreased slowly. For the testing columns with high lateral reinforcement ratio, the load decreases more slowly. At last, the cover concrete falls off seriously with a huge sound, and the longitudinal reinforcement bulged outward with the concrete crushing. 


\section{Effect of test variables on behavior of confined concrete}

Concrete strength Fig. 3 (a) (b) shows the stress-strain curves of confined concrete columns with different concrete strength. All parameters other than the concrete strength of the specimens are the same. It can be seen from the curve in the Fig.3 (a) (b) that the slope of ascending branch of the specimens are consistent, and high strength concrete has a longer elastic stage under the axial compression. It also can be seen from the Fig.3 (a) (b) that the concrete strength has strong influence on the capacity of the confined columns, and the higher the strength is, the greater the capacity is. But with the increase of concrete strength, the descending branch of the curve will become steeper and the ductility get worse, and confinement effect of reinforcement got worse.

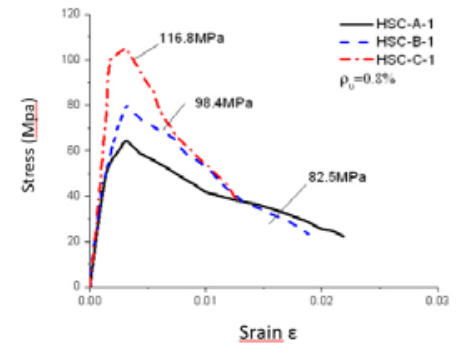

(a)

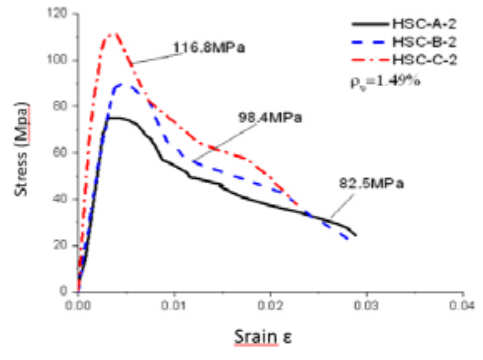

(b)

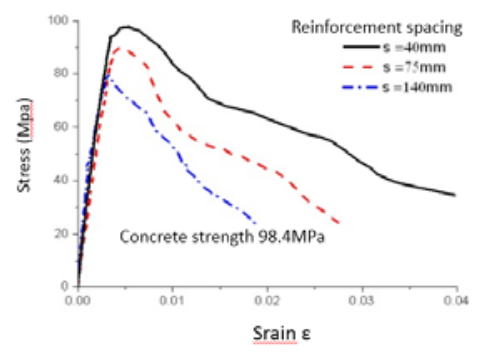

(c)

Fig. 3 Comparison of stress-strain curves of confined concrete columns with different concrete strength (a) (b) and reinforcement spacing(c)

Reinforcement spacing Fig. 3(c) reflects the influence of different reinforcement spacings (40mm 140mm) on the stress-strain curve of the confined concrete columns. It can be seen from the Fig.3(c) that as the reinforcement spacing decrease, the slope of descending branch of the stress-strain curve of confined concrete columns become gentle, and the peak stress and peak strain are greatly increased (Fig. 4(a)(b) and Table 1). When the reinforcement spacing is $40 \mathrm{~mm}$, the peak stress and peak strain of the high-strength confined concrete columns with the strength of $82.5 \mathrm{MPa}$ are increased by $56 \%$ and $148 \%$ than those of the plain concrete columns.

The confinment effect of reinforcement on the concrete is mainly in two aspects: on the one hand, it can provide longitudinal reinforcement with lateral bracing, and delay the early buckling of the longitudinal reinforcement to improve the capacity of the entire reinforcement cage; on the other hand, the hoop constraint of the reinforcement makes the core concrete under three dimensional stress state.

Lateral confinement greatly increases the strength and deformation capacity of the concrete columns. Research by Sheikh et al[6] showed that the confinement force of reinforcement with rectangular section on the core concrete is not distributed as evenly as that of the reinforcement with circular section, and has the maximum value on the cross of the longitudinal and lateral reinforcement. The axial stiffness of the reinforcement plays a leading role, and the lateral constraining force away from the cross part decreases gradually. Decreasing the reinforcement spacing can increase the distribution density of the reinforcement along the longitudinal component, and more core concrete is effectively constrained by the stirrups so that the effective confinement effect of reinforcement can be greatly increased. 


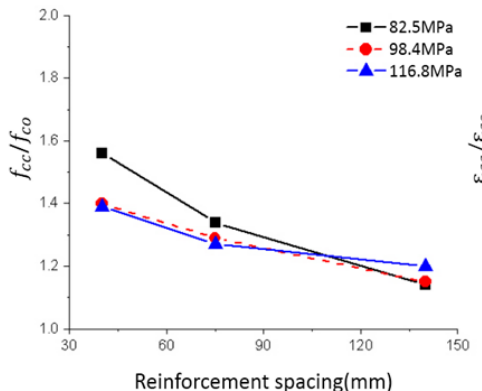

(a)

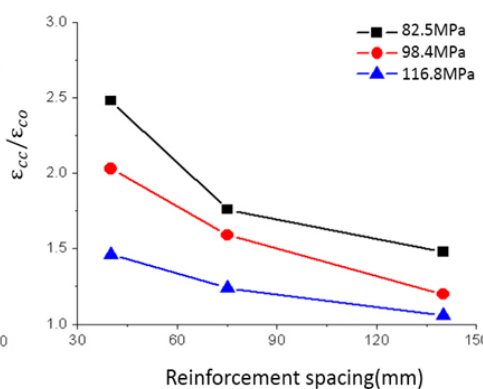

(b)

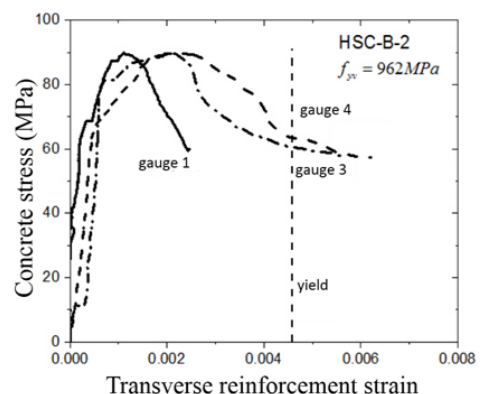

(c)

Fig.4 Influence of reinforcement spacing on the peak stress (a) and strain (b) of confine concrete (c) Concrete stress versus transverse reinforcement strain for column HSC-B-2

Reinforcement stress analysis It can be known from Fig.4(c) and Table 1 that transverse reinforcement did not yield when the concrete reaches the peak stress. At the peak point of stress-strain curve of confined concrete, the transverse reinforcement which cannot yield can provide effective confinement on the core concrete, which has a great impact on descending branch of the stress-strain curve of the confined concrete, and greatly improved the ductility of columns. Therefore, calculating peak stress and strain of the confined concrete using the yield strength of the reinforcement is not accurate. The actual stress of reinforcement should be considered.

\section{Conclusions}

The results of axial compression test of PVA fiber reinforced ultra-high strength concrete columns confined by high-strength reinforcement were presented. With high-strength reinforcement, the concrete compresive strength and ductility of columns improved significantly. Concrete strength and transverse reinforcement spacing influenced behavior of the confined concrete.The ductility decreased with the increase of concrete strength and transverse reinforcement spacing. Given that the high-strength reinforcement did not yield when the specimens reached the peak load, the actual strength of transverse reinforcement should be considered.

\section{Acknowledgements}

This work was financially supported by the Natural Science Foundation of China (51378312).

\section{References}

[1] Concrete Microstructure, Properties and Materials AG Fallis - 2013

[2] Grasley, Zachary C., and D. A. Lange. "Thermal dilation and internal relative humidity of hardened cement paste." Materials \& Structures 40.3(2005):311-317.

[3] Wang, Shasha, M. H. Zhang, and S. T. Quek. "Mechanical behavior of fiber-reinforced high-strength concrete subjected to high strain-rate compressive loading." Construction \& Building Materials 31.6(2012):1-11.

[4] Zhi Y.F.,Niu S.R.,Zhang Y.Z. "Experimental Research on Mechanical Behavior of High-strength Concrete Short Columns Confined with Stirrups" Journal of Chongqing Jianzhu University18.2(1996):53-60

[5] Mander, J. B., M. J. N. Priestley, and R. Park. "Theoretical Stress - Strain Model for Confined Concrete." Journal of Structural Engineering114.8(1988):1804-1826.

[6] Sheikh, Shamim, and S. M. Uzumeri. "Analytical Model for Concrete Confinement in Tied Columns." Journal of the Structural Division108.12(1982):2703-2722. 
[7] Cusson, Daniel, and P. Paultre. "High-Strength Concrete Columns Confined by Rectangular Ties." Journal of Structural Engineering120.3(1994):783-804.

[8] Razvi, S. R., and M. Saatcioglu. "Circular high-strength concrete columns under concentric compression." Aci Structural Journal96.12(1999):págs. 1438-1447

[9] Hong, Ki Nam, S. H. Han, and S. T. Yi. "High-strength concrete columns confined by low-volumetric-ratio lateral ties." Engineering Structures28.9(2006):1346-1353.

[10] Shi Q.X.,Wang N.,Tian J.B.,Shi J.L."A Parctical stress-strain Model for High-Strength Stirrups Confined Concrete" Journal of Building Materials17.2(2014):216-222. 